\title{
Design and Application of Electronic Information Engineering in Industrial Field
}

\author{
Shaozhong Hu \\ Xinyu University, Xinyu, Jiangxi, 338000
}

Keywords: electronic information; industrial field; design and application; sustainable development

\begin{abstract}
With the progress of economic construction, science and technology, the electronic information industry in our country has also developed. Electronic information engineering is a series of analytical and integrated technologies for the information obtained through computers and network technologies. Nowadays, it has penetrated into the research and development applications in various industrial fields, and has played an important role in the progress of enterprises. However, due to the limitations of technologies and time, a lack of experience, uncertainty of market environment and other factors, there are still some defects in electronic information engineering in China. This paper mainly describes the significance of electronic information engineering in the application of modern technology and the problems arising in the development of industry. Besides, this paper also probes into the problem that how electronic information engineering should maintain good situation in order to realize sustainable development.
\end{abstract}

\section{Introduction}

With the gradual deepening of social information technology, various industries need the auxiliary application of electronic information engineering technology. Electronic information engineering means scientific control and effective processing of electronic information through modern computer network technologies, as well as the design and development of electronic equipment and information system. Electronic information engineering integrates modern electronic technology, communication technology and information technology, and is closely related to people's daily life, such as electronic communication, automobile production and manufacturing, construction cost and road transportation, covering many aspects of social development. While in the current period, there is still a lack of technical experience in the field of electronic information in China, and our ability of independent learning and innovation is relatively low. Therefore, in order to promote the healthy scientific progress of electronic information industry, our country needs to focus on the direction and potential energy of the development of electronic information, and increase policy support. Moreover, enterprises should pay attention to training high-tech innovative talents.

\section{Significance of Modern Electronic Information Engineering}

In recent years, the application of electronic information technology not only has a close relationship with people's daily life, production and management, but also has a great impact on the mass production and life style, bringing great convenience. Its important role can be seen everywhere in our real life. In industrial field, a variety of large, complex or elaborate mechanical tools are often used in production, but because of the difficulty of operation of these machineries and equipments, workers lack certain practical technical requirements and the daily maintenance is complicated, which make it difficult to develop the level of industrial production in our country and to achieve substantial results. This has seriously restricted the pace of improving people's living and consumption level. Therefore, the emergence of advanced electronic information technology is capable of solving the problems mentioned above ${ }^{[1]}$. With the progress of computer technology, electronic information continues to deepen, gradually realize macro-control and the overall operational application according to the actual production activities in industrial field, and 
scientifically calculate as well as process various tedious data, which, to a large extent, has reduced the difficulty and intensity of the staff's work as well as improved the working quality and level of factory. At the same time, it is feasible to carry out the corresponding regulation and application for the relevant machineries and equipments, and store efficiently data information in the working process, so as not to cause unnecessary data leakage. Thus, to a large extent, it will avoid a series of testing and maintenance problems.

\section{Problems Arising from Electronic Information Engineering in the Field of Industry}

Although electronic information engineering is becoming more and more important in our country and has significantly improved the living standards of our people as well as the production and operation ability of industry, because of various constraints, there are still some problems to be solved in the development and application of electronic information engineering in the field of industry, such as the duration limitation of technological research and development, the different level of technical experience of staff, the atmosphere of the development of market environment and the unreasonable problems in the construction of all kinds of industrial structure ${ }^{[2]}$. Since the beginning of 1820s, the electronic information industry in China began to develop. In the early stage, people did not pay enough attention to the electronic information industry which has been in a deteriorating trend, resulting in the situation in which China's scientific cognitive technology still has more obvious disadvantages compared with other areas.

The development of information technology in our country began in 1980s. Because people paid little attention at that time, it resulted in the unreasonable and unscientific situation of electronic information engineering industry. Now, as an important part of Chinese industry, electronic information engineering plays an increasing necessary role and produces more industrial value with the development of science and technology. In addition, the value of its added value products is also getting higher and higher. However, since the information technology engineering in our country started late, its development was slow and the profit value of enterprises in most aspects is lower than that of other countries, which make us at a competitive disadvantage in the field of information and to a certain extent, China's overall national strength and international competitiveness have been reduced ${ }^{[3]}$.

Since China's electronic information technology has not received enough attention in the early stage of development, many technologies have been imported, borrowed or directly copied from abroad. We not only have inadequate support from ideological concept, but also produce more unnecessary costs in the aspect of technology development. This is very unfavorable to the competition and cooperation between Chinese industries and foreign enterprises in the economic construction, science and technology.

Most electronic information technologies in our country are imported from abroad in the early stage, which lacks the support of information ideas and related technology platforms. This phenomenon makes the brand creation of electronic information products in our country have obvious defects and loopholes. Some enterprises lack production consciousness of product patents and brands' image. In the economic development situation of globalization, they always hold the traditional solidified production mode and did not have the long-term vision, leading to a clear lack of strength in all aspects of enterprise competition ${ }^{[4]}$.

The traditional research and development mode of electronic information technology and the progress of modern science and technology also make shortcomings gradually appear, for instance, lack clear responsible subjects, the production and demand are difficult to achieve a balanced level, and the process of work management is complex. As a result, the level and efficiency of staff have been greatly reduced, which is not in line with the characteristics of modern information technology management. Under the background of the trend of electronic information engineering, it is very difficult for workers to improve their professional competence and obtain practical operational experience. In the operation of mechanical equipments, it is easy to neglect the precise configuration of various components, resulting in varying degrees of industry losses and resource consumption. 
At present, with the upgrading of computer network, the application of information technology has been extended to many fields, including the electronic information engineering industry. However, some enterprises have not created appropriate management systems according to their own conditions and development needs. Most use the management mode imported from abroad for reference or just do a copy, which result in the omission of system management in the enterprises, and to a great extent increase the risks and challenges of development ${ }^{[5]}$. Electronic information engineering technology management system does not have rich and complete contents. Moreover, its management method is not correct, scientific, flexible and changeable and the implementation of innovative technology is not enough. In the management process, when there are problems that need to be solved urgently, responsibility subjects will shuffle with each other. Concrete affairs can not be carried out on specific technical personnel. All problems mentioned above result in the slow development rate of the entire electronic information technology projects, making it lag behind the pace of the times to a large extent.

\section{Exploration and Application of Electronic Information Engineering in Industrial Field}

With the rapid development of the society, the passive management mode of engineering cost has been transformed into the active management mode. The project scale has grown gradually, and the management contents have become more complicated. Therefore, the construction cost has put forward higher standards and requirements for the development of electronic information engineering. Nowadays, the construction cost has abandoned the management mode of calculation operations by huge manpower. Most of them have begun to develop and apply electronic information technology, use intelligent and automatic information processing, continuously optimize and adjust various departments of industries to achieve the ultimate goal of making the construction cost management system more accurate and the management efficiency greatly improved $^{[6]}$.

In the process of modernization, Radio Frequency Identification Technology has a more obvious effect on people's production and life. For example, in vehicle supply procedure, in order to improve the efficiency of automobile supply chain operation, we acquire the assistance of Radio Frequency Identification Technology in raw material obtainment, access management, orders process and transportation. In the express service industry, the identification and processing of various order codes are very important. Radio Frequency Identification Technology will make it more convenient and accurate to collect all kinds of information of packages, playing an effective role in intelligent electronic information engineering technology.

With the rapid development of various aspects, there are more and more road construction projects. In the process of construction, it is not only necessary to deal with a large number of complex information data, but also very important to manage the construction status, degree of road construction, material loss and cost of manpower as well as material resources in real time. If calculated by manual, they will not only have huge and tedious workload, but also easily appear mistakes in the course of calculation. The gradual development of modern electronic information engineering has brought great convenience to the road construction, which not only saves a lot of labor cost, but also effectively avoids the mistakes in manual calculation, making the management procedure of road construction more scientific and reasonable.

\section{Measures for the Innovation of Electronic Information Engineering}

Under the new social environment advocated by 19th CPC National Congress, innovation and progress are the necessary requirements and standards for the advancement of various industries in our country today. If an industry or a technology wants to achieve a healthy and sustainable development, it must have a high cognitive level and high comprehension ability in concept consciousness. The traditional mode of electronic information engineering does not conform to the characteristics of modern information technology management. Therefore, our country should learn the progress of modern science and technology in the field of electronic information management 
consciousness, combine with experience to simplify the process of office affairs, to implement the main body of responsibility, to integrate theories with practice, to improve the quality and level of people's life, to effectively use the innovative characteristics of information, to provide people with efficient and convenient services, and to innovate and perfect the management system. It is also supposed to adhere to the right idea of holding the customer to the best and trying to meet their real needs, set up the view of love and devotion to employment, enlighten the ideological and moral cognition of workers, improve the service consciousness and comprehensive quality of the staff and let people fully feel that as the unity of economic needs and social development, electronic information technology is to serve people with a good reputation and effective value.

Technical personnel are the key and premise of the progress of electronic information engineering technology. If enterprises want to look at problems from a long-term perspective, technical personnel must be the internal core of the whole enterprise. It is an urgent task for enterprises to cultivate the innovative concepts and technical level of workers, to establish and perfect the reward and punishment mechanism, and to stimulate the staff's unremitting vigor and passion, to create a reasonable platform to improve the construction level of workers, and to strengthen the cultivation and development of technical and innovative talents.

The development of electronic information engineering can not be separated from the support of the state. The government can increase investment in information technology, improve regulations on intellectual property rights of electronic information engineering, optimize market environment, create a harmonious atmosphere, and increase protection efforts. Through the support and encouragement of the government, the reformation and innovation of electronic information technology with Chinese characteristics will be realized.

\section{Conclusion}

To sum up, electronic information engineering technology has been continuously promoted and used. Its value and convenience serve people effectively, not only greatly saving manpower and material costs, but also optimizing data processing procedures. It has also obviously improved the production efficiency of enterprises. Since there are still problems in the progress of electronic information engineering technology in our country, it requires the joint efforts of the state, enterprises and the society to ensure the sustained and healthy development of electronic information technology in industrial field.

\section{References}

[1] Shi Weinan, Li Jianing. Analysis of Technical Measures to Improve Reliability of Power Distribution Network [J]. China Venture Capital, 2017(23).

[2] Chen Chengjie. Analysis of Technical Measures to Improve Reliability of Power Distribution Network [J]. Shandong Industrial Technology, 2017(14):158-158.

[3] Mao Kejie. Reliability Analysis of Power Engineering Technology for Distribution Network [J]. Urban Construction Theory Research: Electronic Version, 2016(12).

[4] Wang Xi. Design and Application of Electronic Information Engineering in Industrial Field [J]. Urban Construction Theory Research: Electronic Version, 2015(22).

[5] Jin Hao. Design and Application of Electronic Information Engineering in Industrial Field [J]. Heilongjiang Science and Technology Information, 2015(19):160-160.

[6] Chen Ling. Design and Application of Electronic Information Engineering in Industrial Field [J]. Electronic Technology \& Software Engineering, 2016(22):97-97. 